\title{
ON THE DIFFERENTIAL DIAGNOSIS OF THROMBOTIC MICROANGIOPATHY IN ENDOMETRIAL CURETTINGS
}

\author{
BY
}

\author{
W. ST. C. SYMMERS \\ From Charing Cross Hospital and Medical School, London
}

(RECEIVED FOR PUBLICATION MAY 9, 1959)

In a paper published three years ago on the histological diagnosis of thrombotic purpura during life I reported three cases in which the characteristic thrombotic microangiopathy was present in biopsy material (Symmers, 1956). In one of the cases the vascular lesions were found in the basal stratum of the endometrium and in endocervical fragments in a specimen obtained by curettage: the operation had been performed because of severe menorrhagia at the onset of the illness, when there were no clinical grounds for suggesting the diagnosis of thrombotic purpura. The patient's satisfactory condition after the curettage and the absence of diagnostic haemato-

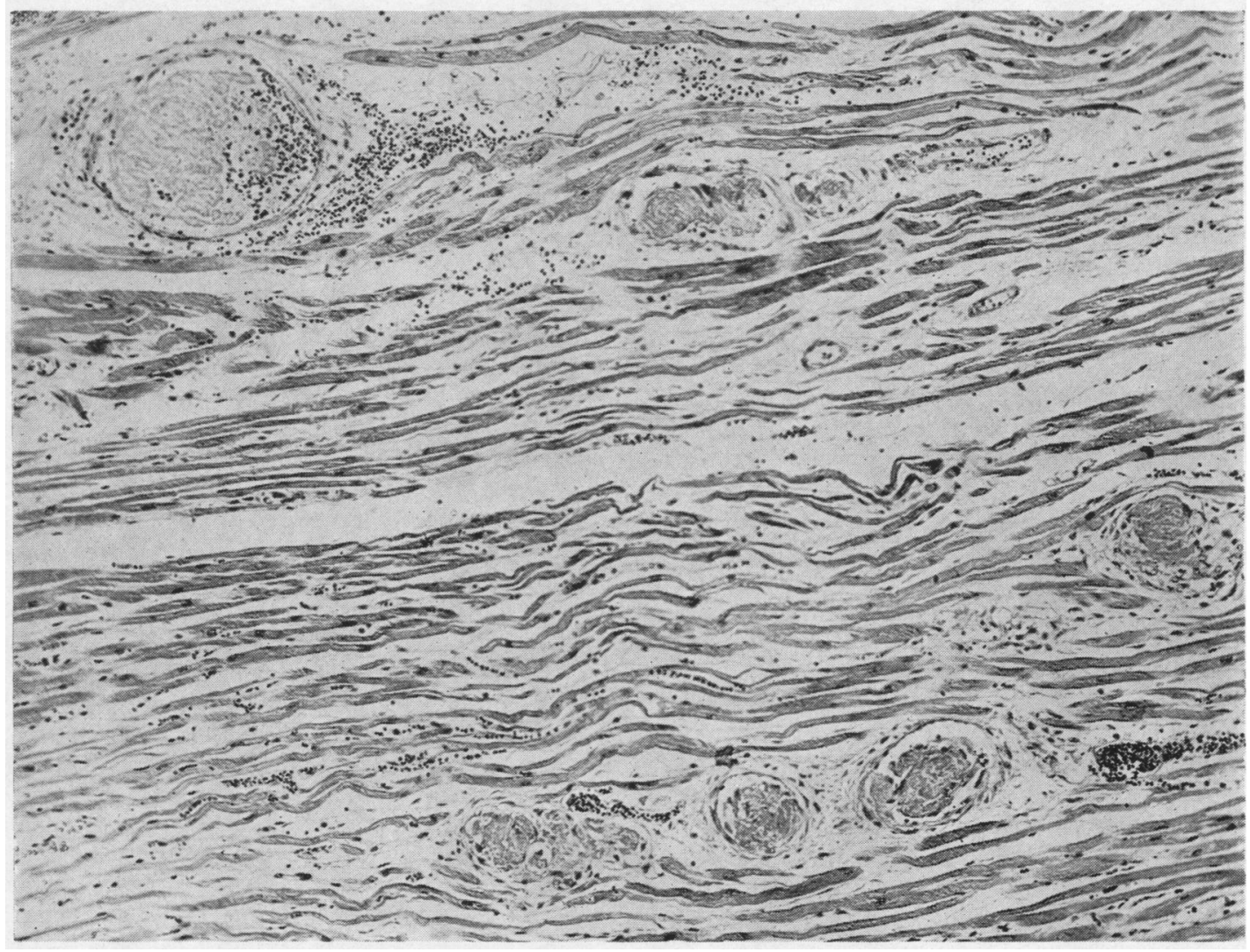

FIG. 1.-Characteristic field of myocardium in a case of thrombotic purpura, showing thrombotic microangiopathy affecting several vessels, which are much dilated and contain granular thrombi. (The black dots in the photograph are erythrocytes.) (Haematoxylin-eosin.) 


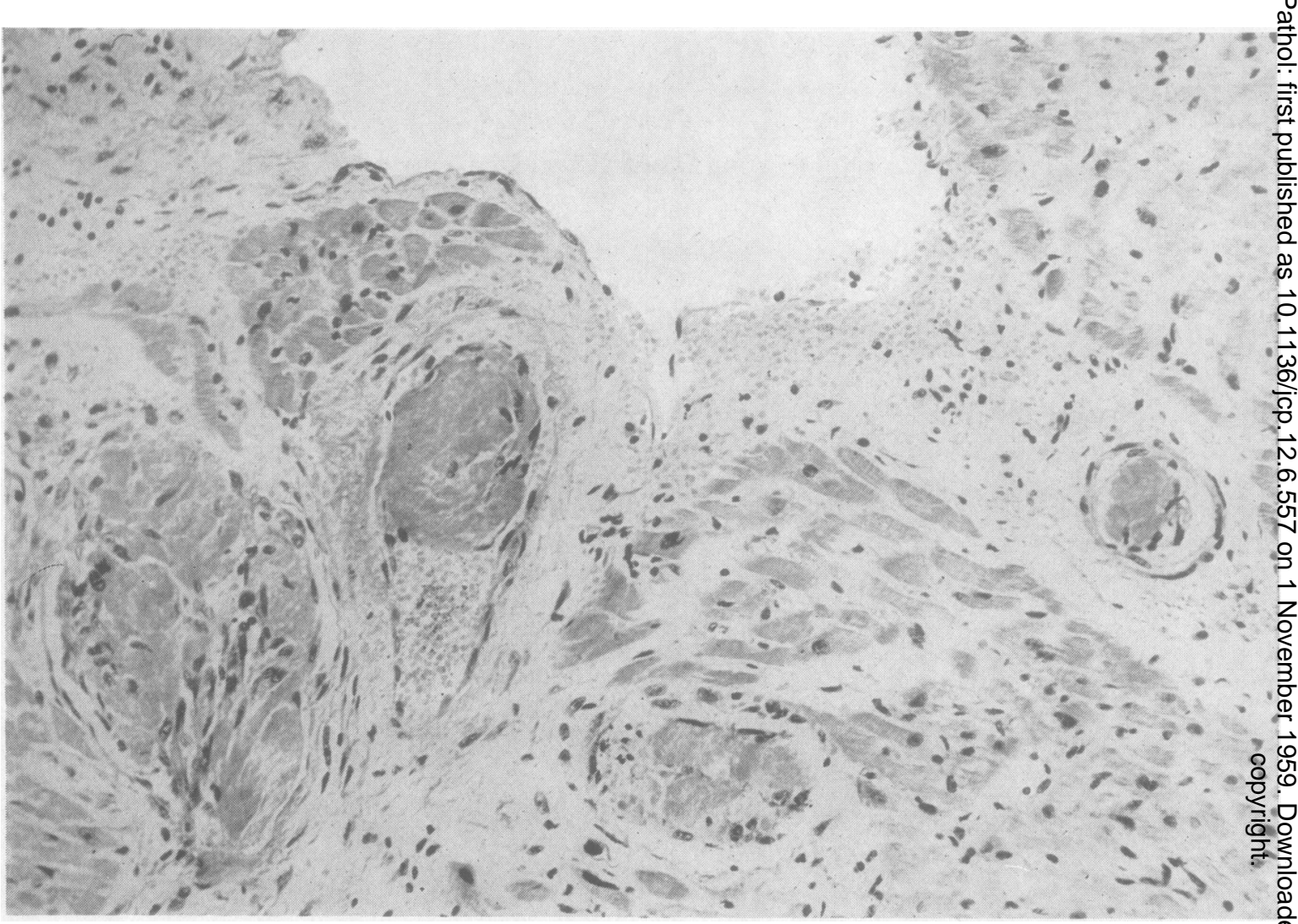

FrG. 2.-High-power view of typical thrombotic microangiopathy in four small myocardial blood vessels in another case of thrombotic purpura. (Haematoxylin-eosin.)

logical abnormalities were felt to be inconsistent with the imminent development of such a striking and rapidly mortal illness as thrombotic purpura : the histological findings were therefore discounted. It was not until three weeks later that the unmistakable clinical syndrome of the disease developed. The diagnosis was confirmed histologically after death. Publication of this case has unfortunately been the cause of some diagnostic confusion, for it has led to banal thrombosis in curettings being misinterpreted as evidence of incipient thrombotic purpura. It seems therefore desirable to write this note in order to draw attention to the possible difficulties, which in fact should be quite readily avoidable.

The paper in which the case report appeared was intended to be essentially clinical in its approach to the role of biopsy in the diagnosis of thrombotic purpura. Histological differential diagnosis was not discussed, having been mentioned, although only briefly, in earlier papers (Symmers, 1952, 1953). The potential frequency of misinterpretation of endometrial vaso- thrombosis began to become familiar through the worrying experiences of colleagues for whom banal thrombosis in curettings had taken on a troublesomely equivocal significance. These experiences made it seem advisable, when working on a general review of the histological diagnosis of some of the so-called "collagen diseases," to say, "Even typical histological lesions do not alone justify the diagnosis [of thrombotic purpura], for they may be closely simulated in some other conditions : thus, these lesions may be mimicked by thrombosed endometrial capillaries and venules in association with haemorrhagic endometrial hyperplasia. . . ." (Symmers, 1958). Banal thrombosis in dilated endometrial blood vessels can in fact simulate the appearances of the typical thrombotic microangiopathy of thrombotic purpura closely enough for mistakes to occur quite readily. The vessels in the superficial parts of the hyperplastic endometrium, particularly venules, are those usually affected; the endometrial hyperplasia may be due to metropathia haemorrhagica or associated with uterine 


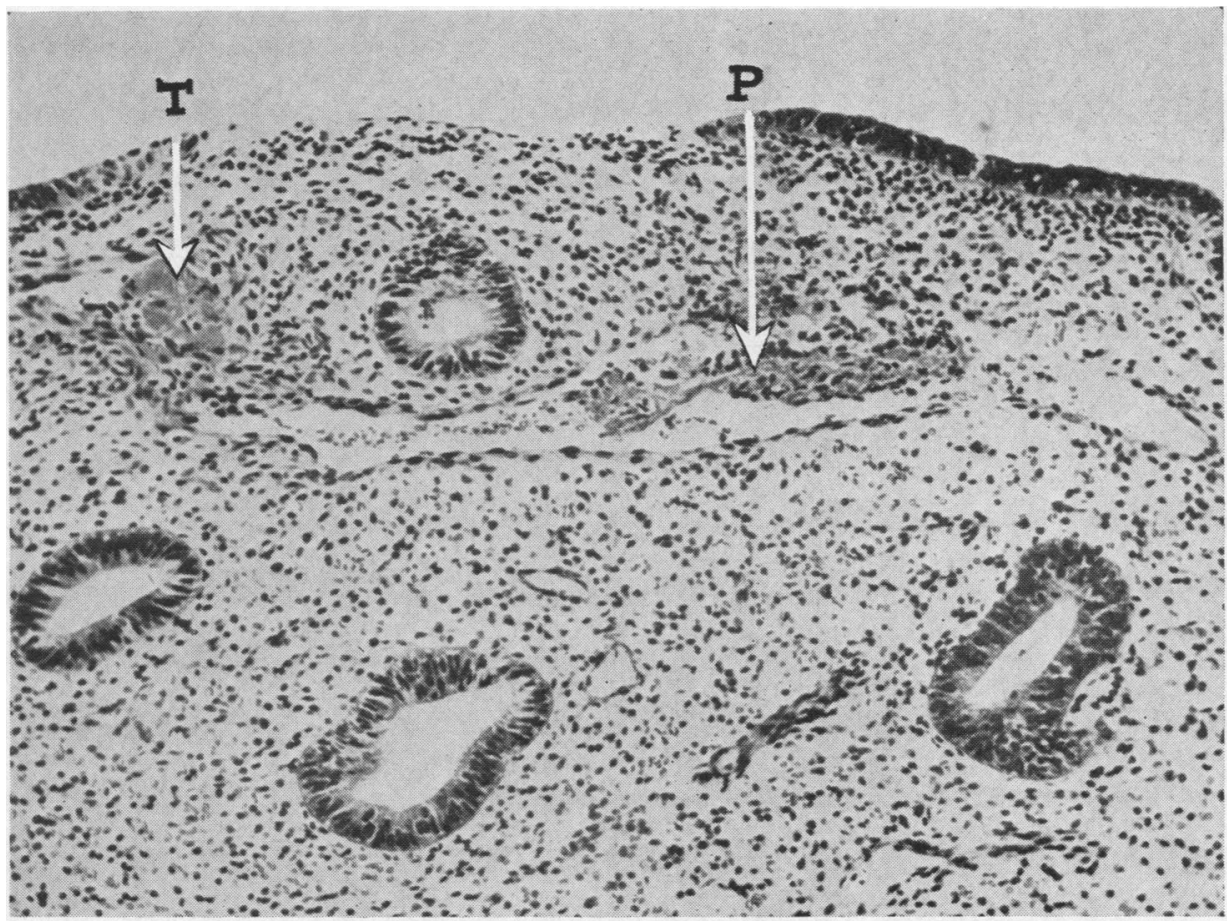

FIG. 3.-The thrombus (T) in the dilated superficial blood vessel in this piece of curetted endometrium from a patient under treatment with an oestrogen was shown in serial sections to be continuous with the seemingly free-lying thrombus (P) within the lumen. The lumen was nowhere completely occluded. The propagated part of the thrombus had acquired a partial covering of endothelium. Dilatation and incomplete occlusion of affected vessels, propagation of thrombus within their lumen, and endothelialization of the surface of the thrombus are usually characteristic of the lesions of thrombotic purpura, and the thrombi do not usually contain much, if any, fibrin. The thrombus illustrated here consisted mainly of fibrin. However, the main factor enabling thrombotic purpura to be excluded in this case was the subsequent failure of any other evidence of this disease to develop. (Haematoxylin-osin.)

fibroids, oestrogen-secreting ovarian tumours, or treatment with oestrogens. In my own experience it has been in the last-mentioned category that this type of thrombosis has been met with most often, and particularly in cases of metrorrhagia in women having treatment with oestrogens for menopausal or postmenopausal disturbances. To some extent, of course, any piece of tissue, small biopsy specimens in particular, in which there is thrombosis of small-calibre blood vessels is liable to comparable misinterpretation.

Paradoxically, mistakes in interpretation of the significance of these banal thrombotic lesions seem likelier to be made by those who have seen the characteristic and widely disseminated vascular lesions of thrombotic purpura in necropsy material. It is as if the observer who is familiar with the striking overall histological picture of thrombotic purpura (Fig. 1) and with the appearance under higher magnification of its individual lesions (Fig. 2) comes to be particularly on the lookout for the presence of any thrombotic lesions in small vessels, and then falls too easily into the trap of dogmatically interpreting all sorts of thrombotic lesions as lesions of thrombotic purpura (Figs. 3 and 4). It is clearly imperative that the histological appearances should always be interpreted in the light of the clinical and haematological findings. A diagnosis of incipient thrombotic purpura on the basis of biopsy findings alone, in other words, as a result of unexpectedly finding an apparently typical thrombotic microangiopathy when there is no clinical and haematological evidence of the disease, demands the greatest circumspection: a vascular lesion which would be acceptable in support of a well-founded clinical diagnosis of thrombotic purpura would have far less diagnostic value when there were no confirmatory clinical and haematological manifestations. Thrombotic purpura can be diagnosed from biopsy material alone only when multiple, typical lesions are present, and never safely on the basis of an isolated finding in a single vessel, although any 


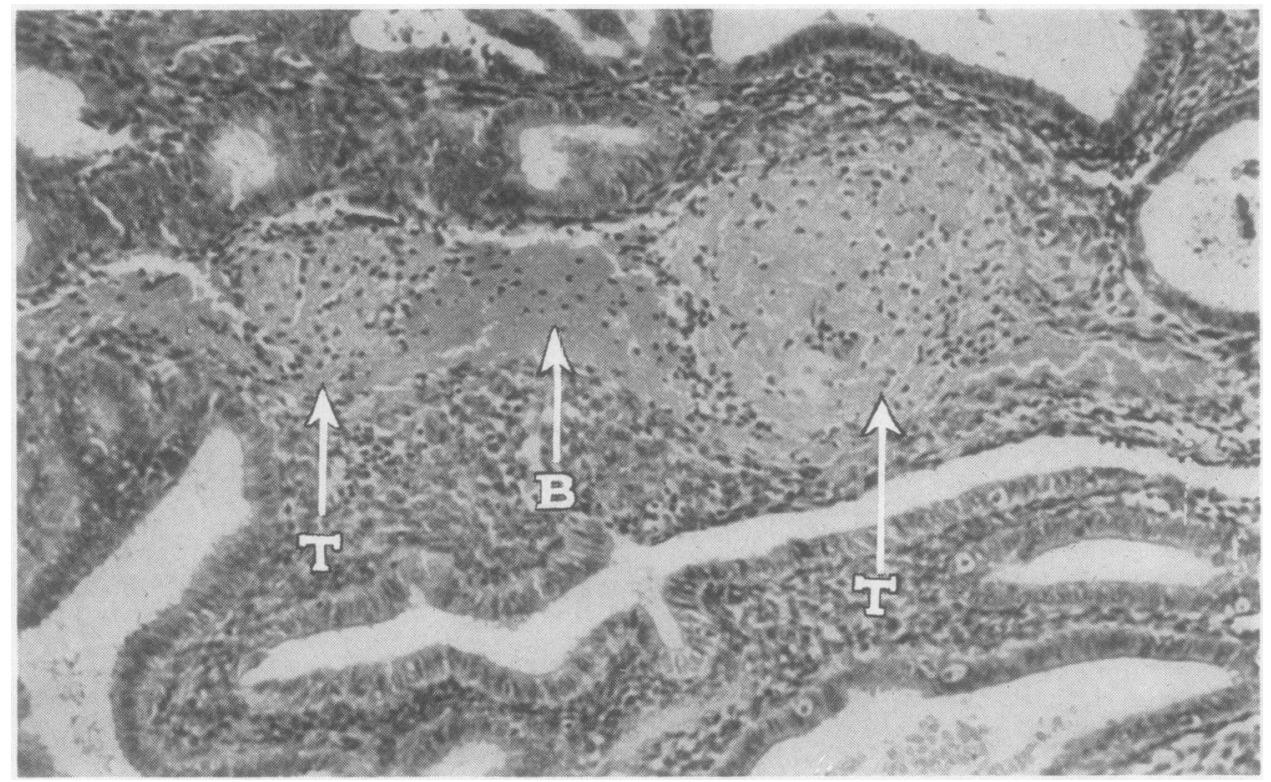

FIG. 4.-The thrombi $(T, T)$ in the dilated vessel in this specimen of endometrium look deceptively like banal thrombi. The patient was already developing the full syndrome of thrombotic purpura when the curettage was performed. Microaneurysm formation without necrosis of the vessel wall or angeitis is a characteristic feature of the thrombotic microangiopathy of thrombotic purpura. There is some degree of microaneurysmal accentuation of the dilatation of the vessel shown here, particularly at the sites of the thrombi, but in fact such dilatation has less diagnostic significance when the vessels affected are such thin-walled and naturally distensible ones as those of endometrium. (B shows blood cells in the engorged and only incompletely obstructed lumen.) (Haematoxylin-eosin.)

such findings must always alert the observer to the possibility of this disease, which has to be recognized early in its course if there is to be the least prospect of treating it successfully.

These remarks could be expanded by discussing the differential diagnosis of thrombotic microangiopathy in detail, but as most of the simulant conditions have been listed in the papers mentioned above it is not proposed to refer to them again here. It is, however, worth stressing that leucocytic infiltration, vasonecrosis, and fibrin-rich thrombi are so very exceptional in the histological picture of thrombotic purpura that their presence in biopsy material should be considered as evidence against this diagnosis.

From the practical point of view, endometrium is the tissue most frequently seen in the biopsy laboratory in which potentially confusing vascular changes are least uncommon, and for this reason it has been chosen as the subject of this note. The principles illustrated by this account are applicable, mutatis mutandis, to other tissues in which thrombosis of the small blood vessels presents a problem in diagnostic interpretation.

\section{Summary}

Attention is drawn to the possibility of mistaking banal thrombosis in small blood vessels in biopsy specimens for the thrombotic microangiopathy of thrombotic purpura. This misinterpretation has been made most frequently in cases of simple endometrial hyperplasia, and may have been encouraged by the author's account (Symmers, 1956) of a case of thrombotic purpura in which the diagnosis was first disclosed by the finding of the typical vascular lesions in a specimen of uterine curettings. Biopsy can prove invaluable as a means of confirming a clinical diagnosis of thrombotic purpura. It is only exceptionally, however, that biopsy findings on their own can warrant making this diagnosis in the absence of supporting clinical and haematological evidence.

\section{REFERENCES}

Symmers, W. St. C. (1952). Brit. med. J., $2,897$.

(1953). Verh. dtsch. Ges. Path., 36, 224.

(1956). Lancet, 1, 592 .

(1958). In Eight Colloquia on Clinical Pathology, ed. Welsch, M. Dustin, P., and Dagnelie, J., ch. 29, p. 749. Presses Académiques Européennes, Brussels. 